\title{
Survey on prevalence of lower urinary tract symptoms in an Asian population
}

\author{
CH Yee *, CK Chan, Jeremy YC Teoh, Peter KF Chiu, Joseph HM Wong, Eddie SY Chan, \\ Simon SM Hou, CF Ng
}

This article was published on 18 Jan 2019 at www.hkmj.org.

\section{A B S T R A C T}

Introduction: Lower urinary tract symptoms (LUTS) have a strong effect on socio-economic and individual quality of life. The aim of the present study was to investigate the prevalence of LUTS in an Asian population.

Methods: A telephone survey of individuals aged $\geq 40$ years and of Chinese ethnicity was conducted. The survey included basic demographics, medical and health history, drinking habits, International Prostate Symptom Score, overactive bladder symptom score, Patient Health Questionnaire (PHQ-9) score, and Short Form (SF)-12v2 score.

Results: From March to May 2017, 18881 calls were made, of which 1543 fulfilled the inclusion criteria. In the end, 1000 successful respondents were recruited (302 men and 698 women). Age-adjusted prevalence of overactive bladder syndrome was $15.1 \%$. The older the respondent, the more prevalent the storage symptoms and voiding symptoms (storage symptoms: $r=0.434, \quad \mathrm{P}<0.001$; voiding symptom: $r=0.190, \mathrm{P}<0.001)$. Presence of hypertension and diabetes were found to be significantly and positively correlated with storage and voiding symptoms. Storage and voiding symptoms were found to affect
PHQ-9 scores (storage symptoms: $r=0.257, \mathrm{P}<0.001$; voiding symptoms: $r=0.275, \mathrm{P}<0.001)$ and $\mathrm{SF}-12 \mathrm{v} 2$ scores (storage symptoms: $r=0.467, \mathrm{P}<0.001$; voiding symptoms: $r=0.335 ; \mathrm{P}<0.001)$. Nocturia was the most prominent symptom among patients who sought medical help for their LUTS.

Conclusions: Lower urinary tract symptoms are common in Asian populations. Both storage and voiding symptoms have a negative impact on mental health and general well-being of individuals.

\section{Hong Kong Med J 2019;25:13-20 \\ https://doi.org/10.12809/hkmj187502}

CH Yee *, MB, BS, FRCSEd

CK Chan, MB, ChB, FRCSEd

JYC Teoh, MB, BS, FRCSEd

PKF Chiu, MB, ChB, FRCSEd

JHM Wong, MB, BS, FRCSEd

ESY Chan, MB, ChB, FRCSEd

SSM Hou, MB, BS, FRCSEd

CF Ng, MB, BS, FRCSEd

SH Ho Urology Centre, The Chinese University of Hong Kong, Shatin, Hong Kong

* Corresponding author: yeechihang@surgery.cuhk.edu.hk

New knowledge added by this study

- Past studies on lower urinary tract symptoms (LUTS) prevalence have mainly involved men. The present study provides data on the prevalence of LUTS in both sexes.

- The present study is among the few studies which have correlated LUTS with general well-being and mental health.

- There is a discrepancy between LUTS and medical help seeking behaviour. The present study provides insight into symptoms that drive patients to seek medical help.

Implications for clinical practice or policy

- Understanding the prevalence of LUTS will help estimate the associated workload and expense needed to take care of this group of patients.

- The discrepancy between LUTS prevalence and the medical help seeking behaviour of patients with LUTS suggests a need for public health education.

\section{Introduction}

Lower urinary tract symptoms (LUTS) can affect patients of both sexes and of all ages. ${ }^{1}$ Although LUTS are regarded by the most cultures as an inevitable consequence of ageing, bother from LUTS varies among populations. ${ }^{2}$ Assessment of bother from symptoms is important, because the degree of bother affects quality of life (QoL) and medical help seeking behaviour. ${ }^{3,4}$
There are few studies investigating the correlation between LUTS and drinking habits, especially among Asian populations. Daily routines and dietary habits are largely dependent on cultural background; therefore, LUTS might vary in this perspective. In addition, up-to-date evidence on the impact of LUTS on mental health, as well as on the general well-being of an individual, is scarce. Most studies have investigated LUTS as a collective 


\section{亞洲人口下尿路症狀現患率調查}

\section{余知行、陳自覺、張源津、趙家鋒、黃翰明、陳樹賢、 侯仕明、吳志輝}

引言：下尿路症狀對社會經濟及個人生活質量有重大影響。本研究旨 在檢視亞洲人口下尿路症狀的現患率。

方法: 對40歲或以上華人進行電話調查, 調查內容包括基本人口統計 學、醫療及健康史、飲酒習慣、國際前列腺症狀評分、膀胱過度活躍 症狀評分、患者健康問卷（PHQ-9）評分及標準十二題簡明健康狀況 調查表第二版 $(\mathrm{SF}-12 \mathrm{v} 2)$ 評分。

結果：2017年 3 月至 5 月期間共撥打 18881 次電話, 其中 1543 次符合 納入標準, 最終招募1000名成功受訪者（包括302名男性和698名女 性）。經年齡調整的膀胱過度活躍現患率為 $15.1 \%$ 。受訪者年齡越 大, 儲尿期和排尿期症狀便越普遍（儲存症狀： $r=0.434, \mathrm{P}<0.001$; 排尿症狀： $r=0.190, \mathrm{P}<0.001)$ 。高血壓和糖尿病患者較易出現儲 尿期和排尿期症狀。儲尿期和排尿期症狀會影響PHQ-9評分（儲存 症狀： $r=0.257, \mathrm{P}<0.001$; 排尿症狀 $: r=0.275, \mathrm{P}<0.001)$ 和SF$12 \mathrm{v} 2$ 評分（儲存症狀： $r=0.467, \mathrm{P}<0.001$; 排尿症狀 $: r=0.335$, $\mathrm{P}<0.001 ）$ 。夜尿症是下尿路症狀患者求醫時的最常見症狀。

結論：下尿路症狀在亞洲人口中很常見。儲尿期和排尿期症狀對個人 心理健康和一般生活情況皆產生負面影響。 symptom entity. ${ }^{5}$ Few studies have investigated the relationship between individual symptoms and psychological stress.

The purpose of the present study is to provide an updated perspective on LUTS in an Asian population including both men and women. The present study aimed to clarify the prevalence of the subcategories of LUTS-voiding symptoms, storage symptoms, and nocturia-through a telephone survey. Furthermore, we investigated medical background and lifestyle factors that might have precipitated LUTS. Last, we assessed the effect of LUTS on the mental health and general well-being of individual patients. We also evaluated the level of bother caused by individual symptoms in relation to medical help seeking behaviour.

\section{Methods}

This was a random telephone survey of the general population in Hong Kong. Inclusion criteria were men or women aged $\geq 40$ years of Chinese ethnicity. Subjects who were not able to comprehend the telephone survey were excluded from the study. Local census data report a $\geq 40$-year-old population of 3875800 in $2013 .{ }^{6}$ Anticipating a confidence level of $95 \%$ and margin of error of 3\%, 1000 respondents were targeted to complete the survey.

The survey consisted of seven parts. Basic demographics were collected, including age, sex, marital status, education level, occupation, and individual monthly income. Medical background and drinking habits were explored by questions on smoking history, beverage consumption habits, general medical and mental health history, urological history, and medical help seeking behaviour. Any LUTS were assessed with the International Prostate Symptom Score (IPSS) or the overactive bladder symptom score. ${ }^{7}$ The Patient Health Questionnaire-9 (PHQ-9) was used to assess depressive symptoms among the respondents. The PHQ-9 scores $\geq 10$ have a sensitivity of $88 \%$ and a specificity of $88 \%$ for major depression. The PHQ-9 scores of 5, 10, 15, and 20 represent mild, moderate, moderately severe, and severe depression, respectively. ${ }^{8}$ The Short Form (SF)-12v2 Health Survey was used to assess health-related QoL. The International Index of Erectile Function was used to assess sexual function in male respondents who were sexually active in the preceding 4 weeks. ${ }^{9}$ Figure 1 shows the survey question flow. To avoid unnecessary embarrassment and to improve compliance, questions on sexual health were asked by a pre-recorded computergenerated voice programme. Subjects answered the questions by pressing the appropriate number key on the phone keypad.

The interviews were carried out from March to May 2017. To minimise the sampling error, telephone numbers were first selected randomly from an updated telephone directory as seed numbers. Another three sets of numbers were then generated using randomisation of the last two digitals to recruit unlisted numbers. Duplicate numbers were screened out, and the remaining numbers were mixed in a random order to become the final sample. Interviews were carried out by experienced interviewers, between 18:00 and 22:00 on weekdays or at other convenient times, including weekends and public holidays, arranged with suitable subjects. Upon successful contact with a target household,

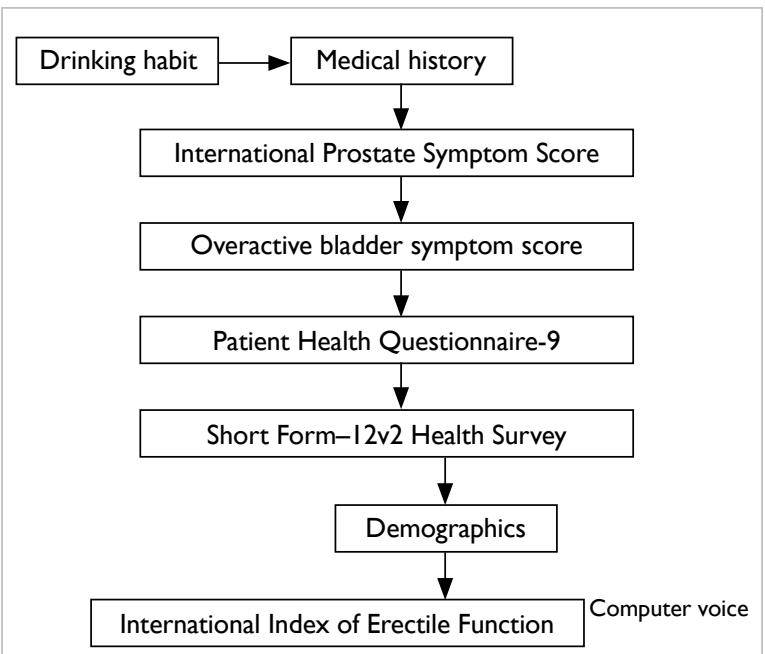

FIG I. Survey flow 
one qualified member of the household was selected among those family members using the last-birthday random selection method (ie, the respondent aged $\geq 40$ years in a household who had most recently had a birthday would be selected to participate in the telephone interview). Principles of the Declaration of Helsinki were followed. The study was performed in compliance with Good Clinical Practice. All participants provided informed consent before participating in the study.

Descriptive statistics were used to characterise the clinical characteristics of the survey cohort. Spearman correlation was used to investigate the relationships between different age-groups and severity of LUTS. Chi squared test or Fisher's exact test was applied for categorical data. Univariate and multivariable logistic regression analyses were performed to identify clinical covariates that were significantly associated with LUTS. The P value of $<0.05$ were considered statistically significant. The SPSS (Windows version 24.0; IBM Corp, Armonk [NY], US) was used for all calculations.

\section{Results}

A total of 18881 calls were made, among which 17338 were invalid cases, including non-residential lines, invalid lines, non-eligible respondents, or having the line cut immediately before the survey could start. Another 543 eligible respondents were excluded because they refused to participate in the survey after being informed of the nature of the study. In the end we received 1000 valid responses, achieving a response rate of $64.8 \%$ after excluding the invalid numbers. Table 1 includes the demographics of the respondents and their drinking habits. Most respondents did not regularly drink coffee, but $30.5 \%$ of respondents reported drinking tea more than once per day.

In total, 774 respondents $(77.4 \%)$ reported a certain degree of LUTS (Table 2). Among respondents with LUTS, $89.5 \%$ had mild symptoms, $8.9 \%$ had moderate symptoms, and $1.6 \%$ experience severe symptoms. Men had more LUTS than did women (mean \pm standard deviation [SD]: men, 3.62 \pm 4.86 ; women, $2.56 \pm 3.34 ; \mathrm{P}=0.002$ ). The older the subject, the poorer the LUTS and QoL scores (mean IPSS: $40-59$ years, $1.37 \pm 2.05$; 60-79 years, $3.32 \pm$ 4.28 ; $\geq 80$ years, $4.48 \pm 4.45 ; \mathrm{P}<0.001$; mean QoL score: 40-59 years, $1.15 \pm 0.91 ; 60-79$ years, $1.85 \pm 1.13 ; \geq 80$ years, $2.25 \pm 1.13 ; \mathrm{P}<0.001)$. In the storage symptom domain of IPSS, sex did not show any significant difference in mean total storage symptom score (men, $2.32 \pm 2.48$; women, $1.91 \pm 1.97 ; \mathrm{P}=0.052$ ). The older the age, the more prevalent the storage and voiding symptoms (storage symptom score: $r=0.434$, $\mathrm{P}<0.001$; voiding symptom score: $r=0.190, \mathrm{P}<0.001$ ). Mean total storage symptom score across different age-groups were: 40-59 years, $1.01 \pm 1.29$; 60-79 years, $2.30 \pm 2.27 ; \geq 80$ years, $3.23 \pm 2.25 ; \mathrm{P}<0.001$. The age-adjusted prevalence of any urgency symptom in our survey was 15096 per 100000 population. If we only include symptoms of urgency more than once per week, the age-adjusted prevalence was 4070 per 100000 population. Furthermore, more storage symptoms than voiding symptoms were experienced by respondents at any age-group (Fig 2).

If we exclude nocturia 1 time per night only as part of LUTS or part of storage symptoms, a total of $191(63.2 \%)$ men were found to have LUTS in this survey. In this group of respondents, 71 (37.2\%) reported only having storage symptoms, 19 (9.9\%) reported only having voiding symptoms, and 101 (52.9\%) reported having both storage and voiding symptoms. Similarly, 348 (49.9\%) women were found to have LUTS: 181 (52.0\%) reported only having storage symptoms, 19 (5.5\%) reported only having voiding symptoms, and 148 (42.5\%) reported having both storage and voiding symptoms.

Figure 3 shows the prevalence of nocturia among the respondents with LUTS. Among those with LUTS, 128 (67.0\%) men and 230 (66.1\%) women reported having nocturia twice or more per night. The median number of nocturia episodes increased with age (men, $r=0.510 ; \mathrm{P}<0.001$; women, $r=0.418$; $\mathrm{P}<0.001)$.

Table 1 includes the general health status and mental health status of the respondents by means of SF-12v2 score and PHQ score, respectively. As shown in Table 3, both PHQ-9 scores and SF-12v2 scores were found to be correlated with both storage symptoms and voiding symptoms. The higher the PHQ-9 score-indicating more prominent depressive symptoms-the more significant the LUTS. Similarly, in the SF-12v2 assessment of general health, the higher the score-indicating poorer health-the more significant LUTS. Storage symptoms and voiding symptoms were found to be negatively correlated with all components of the SF$12 \mathrm{v} 2$.

The results of storage and voiding symptoms regression analysis are shown in Table 3. Age, presence of hypertension, and diabetes were found to be significantly correlated with storage symptoms. In contrast, male sex, presence of hypertension, diabetes, ischaemic heart disease, and stroke were found to be significantly positively correlated with voiding symptoms.

Concerning medical help seeking behaviour among men, $37.5 \%$ of men with severe LUTS, $16.7 \%$ with moderate LUTS, and $7.9 \%$ with mild LUTS sought medical help. No women with moderate LUTS sought medical help. For women with mild LUTS, $2.5 \%$ sought medical help. Among the patients with LUTS who sought medical help, the most prominent symptoms were nocturia (mean IPSS, $1.80 \pm 1.32$ ) and urgency (mean IPSS, $0.97 \pm 1.67$ ). 
TABLE I. Demographics of the respondents and their general health status

\begin{tabular}{|c|c|c|c|}
\hline & Men $(n=302)$ & Women $(n=698)$ & Total $(n=1000)$ \\
\hline \multicolumn{4}{|l|}{ Age (years) } \\
\hline $40-49$ & $49(16.2 \%)$ & $83(11.9 \%)$ & $132(13.2 \%)$ \\
\hline $50-59$ & $36(11.9 \%)$ & $159(22.8 \%)$ & $195(19.5 \%)$ \\
\hline $60-69$ & $87(28.8 \%)$ & 205 (29.4\%) & $292(29.2 \%)$ \\
\hline $70-79$ & $77(25.5 \%)$ & $136(19.5 \%)$ & $213(21.3 \%)$ \\
\hline $80-89$ & $49(16.2 \%)$ & $105(15.0 \%)$ & $154(15.4 \%)$ \\
\hline $90-100$ & $4(1.3 \%)$ & $9(1.3 \%)$ & $13(1.3 \%)$ \\
\hline Missing data & 0 & $1(0.1 \%)$ & $1(0.1 \%)$ \\
\hline \multicolumn{4}{|l|}{ Marital status } \\
\hline Married & 249 (82.5\%) & $564(80.8 \%)$ & $813(81.3 \%)$ \\
\hline Single & $28(9.3 \%)$ & $45(6.5 \%)$ & $73(7.3 \%)$ \\
\hline Cohabited & 0 & $1(0.1 \%)$ & $1(0.1 \%)$ \\
\hline Divorced/widowed/separated & $25(8.3 \%)$ & $86(12.3 \%)$ & $111(11.1 \%)$ \\
\hline Missing data & 0 & $2(0.3 \%)$ & $2(0.2 \%)$ \\
\hline \multicolumn{4}{|l|}{ Education level } \\
\hline Primary school or below & $93(30.8 \%)$ & $353(50.6 \%)$ & $446(44.6 \%)$ \\
\hline Secondary school & $150(49.7 \%)$ & $245(35.1 \%)$ & 395 (39.5\%) \\
\hline College/university or above & $58(19.2 \%)$ & $96(13.7 \%)$ & $154(15.4 \%)$ \\
\hline Missing data & $1(0.3 \%)$ & $4(0.6 \%)$ & $5(0.5 \%)$ \\
\hline \multicolumn{4}{|l|}{ Occupation } \\
\hline Unemployed & $7(2.3 \%)$ & $4(0.6 \%)$ & $11(1.1 \%)$ \\
\hline Professionals & $15(5.0 \%)$ & $12(1.7 \%)$ & $27(2.7 \%)$ \\
\hline Service industry & $21(7.0 \%)$ & $27(3.9 \%)$ & $48(4.8 \%)$ \\
\hline Manual workers & $31(10.3 \%)$ & $20(2.9 \%)$ & $51(5.1 \%)$ \\
\hline Freelance workers & $5(1.7 \%)$ & $9(1.3 \%)$ & $14(1.4 \%)$ \\
\hline Corporate employees & $19(6.3 \%)$ & $31(4.4 \%)$ & $50(5.0 \%)$ \\
\hline Housewives/househusbands & $1(0.3 \%)$ & $372(53.3 \%)$ & $373(37.3 \%)$ \\
\hline Retired & $200(66.2 \%)$ & $214(30.7 \%)$ & $414(41.4 \%)$ \\
\hline Others & $3(1.0 \%)$ & $9(1.3 \%)$ & $12(1.2 \%)$ \\
\hline \multicolumn{4}{|l|}{ Smoking status } \\
\hline Non-smoker & $224(74.2 \%)$ & $657(94.1 \%)$ & $881(88.1 \%)$ \\
\hline Ex-smoker & $42(13.9 \%)$ & $15(2.2 \%)$ & $57(5.7 \%)$ \\
\hline Current smoker & $36(11.9 \%)$ & $26(3.7 \%)$ & $62(6.2 \%)$ \\
\hline \multicolumn{4}{|l|}{ Frequency of coffee intake } \\
\hline Never & $163(54.0 \%)$ & $479(68.6 \%)$ & $642(64.2 \%)$ \\
\hline$<1$ time per week & $34(11.2 \%)$ & $56(8.0 \%)$ & $90(9.0 \%)$ \\
\hline 1-6 times per week & $35(11.6 \%)$ & $51(7.3 \%)$ & $86(8.6 \%)$ \\
\hline 1 time per day & $67(22.2 \%)$ & $107(15.3 \%)$ & $174(17.4 \%)$ \\
\hline$>1$ time per day & $3(1.0 \%)$ & $5(0.7 \%)$ & $8(0.8 \%)$ \\
\hline \multicolumn{4}{|l|}{ Frequency of tea drinking } \\
\hline Never & $96(31.8 \%)$ & $282(40.4 \%)$ & $378(37.8 \%)$ \\
\hline$<1$ time per week & $38(12.6 \%)$ & $89(12.8 \%)$ & $127(12.7 \%)$ \\
\hline 1-6 times per week & $60(20.0 \%)$ & $130(18.6 \%)$ & $190(19.0 \%)$ \\
\hline$\geq 1$ time per day & $108(35.8 \%)$ & $197(28.2 \%)$ & $305(30.5 \%)$ \\
\hline \multicolumn{4}{|c|}{ Frequency of caffeinated soft drink intake } \\
\hline Never & $249(82.5 \%)$ & $620(88.8 \%)$ & 869 (86.9\%) \\
\hline$<1$ time per week & $40(13.2 \%)$ & $63(9.0 \%)$ & $103(10.3 \%)$ \\
\hline$\geq 1$ time per week & $13(4.3 \%)$ & $15(2.1 \%)$ & $28(2.8 \%)$ \\
\hline \multicolumn{4}{|l|}{ Patient health questionnaire-9 score } \\
\hline 0-4 (No symptom) & $269(89.1 \%)$ & $632(90.5 \%)$ & $901(90.1 \%)$ \\
\hline 5-9 (Minimal symptoms) & $27(8.9 \%)$ & $56(8.0 \%)$ & $83(8.3 \%)$ \\
\hline 10-14 (Minor depression) & $4(1.4 \%)$ & $8(1.1 \%)$ & $12(1.2 \%)$ \\
\hline 15-19 (Moderate depression) & $1(0.3 \%)$ & $1(0.2 \%)$ & $2(0.2 \%)$ \\
\hline$\geq 20$ (Severe depression) & $1(0.3 \%)$ & 0 & $1(0.1 \%)$ \\
\hline Missing data & 0 & $1(0.2 \%)$ & $1(0.1 \%)$ \\
\hline \multicolumn{4}{|c|}{ Short Form (SF)-12v2 (general health) } \\
\hline Excellent & $3(1.0 \%)$ & $7(1.0 \%)$ & $10(1.0 \%)$ \\
\hline Very good & $64(21.2 \%)$ & 159 (22.8\%) & $223(22.3 \%)$ \\
\hline Good & $116(38.4 \%)$ & 262 (37.5\%) & 378 (37.8\%) \\
\hline Fair & $100(33.1 \%)$ & $234(33.5 \%)$ & $334(33.4 \%)$ \\
\hline Poor & 19 (6.3\%) & $35(5.0 \%)$ & $54(5.4 \%)$ \\
\hline Missing data & 0 & $1(0.2 \%)$ & $1(0.1 \%)$ \\
\hline
\end{tabular}


TABLE 2. Prevalence of urinary symptoms among respondents

\begin{tabular}{|c|c|c|c|c|c|c|}
\hline & \multicolumn{3}{|c|}{ Age-groups in men (years, $n=302$ ) } & \multicolumn{3}{|c|}{ Age-groups in women (years, $n=698)^{\star}$} \\
\hline & $40-59(n=85)$ & $60-79(n=164)$ & $80-100(n=53)$ & $40-59(n=242)$ & $60-79(n=341)$ & $80-100(n=114)$ \\
\hline \multicolumn{7}{|l|}{ LUTS in general } \\
\hline No LUTS (IPSS 0) & $38(44.7 \%)$ & $26(15.9 \%)$ & $3(5.7 \%)$ & $94(38.8 \%)$ & $58(17.0 \%)$ & $6(5.3 \%)$ \\
\hline Mild (IPSS 1-7) & $46(54.1 \%)$ & $118(72.0 \%)$ & $39(73.6 \%)$ & $144(59.5 \%)$ & $253(74.2 \%)$ & $93(81.6 \%)$ \\
\hline Moderate (IPSS 8-19) & $1(1.2 \%)$ & $15(9.1 \%)$ & $8(15.1 \%)$ & $4(1.7 \%)$ & $26(7.6 \%)$ & $15(13.2 \%)$ \\
\hline Severe (IPSS 20-35) & 0 & $5(3.0 \%)$ & $3(5.7 \%)$ & 0 & $4(1.2 \%)$ & 0 \\
\hline LUTS with urgency & $6(7.1 \%)$ & $32(19.5 \%)$ & $21(39.6 \%)$ & $29(12.0 \%)$ & $70(20.8 \%)$ & $34(29.8 \%)$ \\
\hline With urge incontinence & $3(3.5 \%)$ & $24(14.6 \%)$ & $15(28.3 \%)$ & $18(7.4 \%)$ & $44(13.1 \%)$ & $29(25.4 \%)$ \\
\hline LUTS with urgency $\geq 1$ time per week & $1(1.2 \%)$ & $14(8.5 \%)$ & $11(20.8 \%)$ & $4(1.7 \%)$ & 18 (5.3\%) & $15(13.2 \%)$ \\
\hline With urge incontinence & $1(1.2 \%)$ & $11(6.7 \%)$ & $11(20.8 \%)$ & $4(1.7 \%)$ & $17(5.0 \%)$ & $14(12.3 \%)$ \\
\hline
\end{tabular}

Abbreviations: IPSS = International Prostate Symptom Score; LUTS = lower urinary tract symptom

* One respondent was excluded from analysis because she failed to report her age

\section{Discussion}

In general, LUTS include storage symptoms and voiding symptoms. Storage symptoms include urinary frequency, nocturia, urinary urgency, and urinary incontinence. Voiding symptoms include slow stream, intermittent stream, hesitancy, and straining. ${ }^{10}$

According to our survey, $77.8 \%$ of men and $77.3 \%$ of women aged $\geq 40$ years reported at least mild degree of LUTS according to IPSS assessment. This prevalence was relatively lower than an internet survey carried out in mainland China, Taiwan and South Korea, which reported $86.8 \%$ of participants having at least mild symptoms on IPSS. ${ }^{1}$ However, our findings were comparable to the EpiLUTS study performed in the US, the United Kingdom and Sweden, which demonstrated the prevalence of at least one LUTS was $72.3 \%$ for men and $76.3 \%$ for women. ${ }^{11}$ In a study of LUTS in Canada, Germany, Italy, Sweden, and the United Kingdom, Irwin et al ${ }^{12}$ reported an even lower prevalence of LUTS, with an overall prevalence of any LUTS of $62.5 \%$ in men and $66.6 \%$ in women. Although such differences in LUTS prevalence across studies could be attributed to different populations, different cultural backgrounds or methodological variations could also account for this observation. Linguistic interpretation discrepancy and different levels of severity or frequency being used to determine the presence of symptoms would also generate different results. In addition, changes in general health awareness and in the socio-economic environment might also effect survey outcomes. Furthermore, some studies have suggested seasonal variations of LUTS, with symptoms being more prominent in winter. ${ }^{13,14}$ Our survey was carried out in spring and early summer, which could possibly account for our results falling into the median range in the literature.

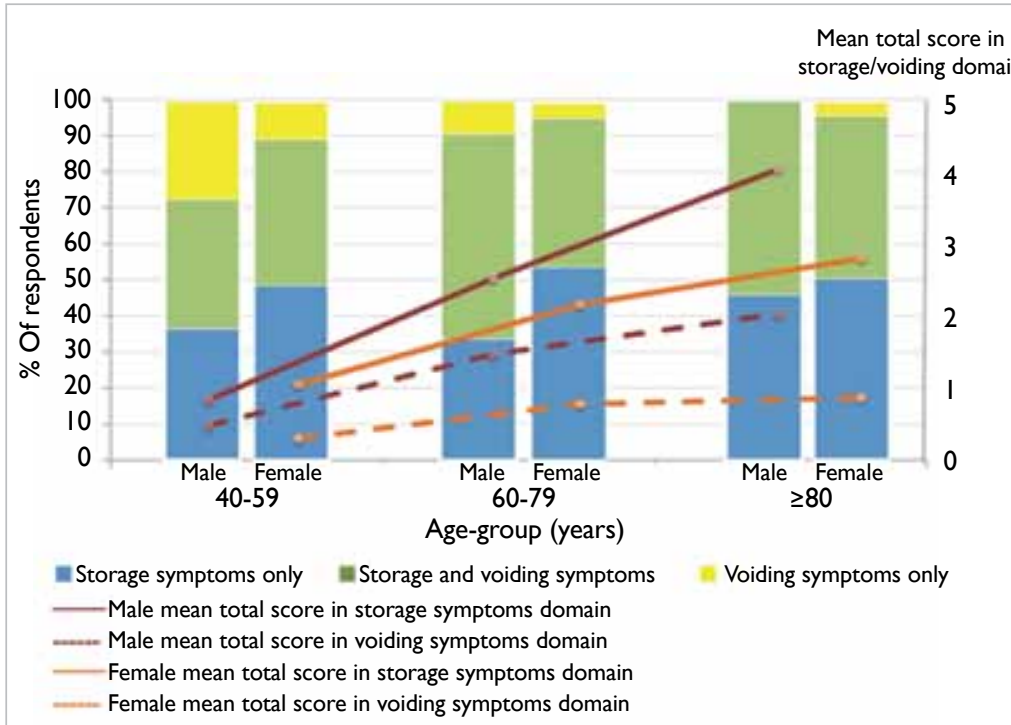

FIG 2. Storage and voiding symptoms in respondents with lower urinary tract symptoms

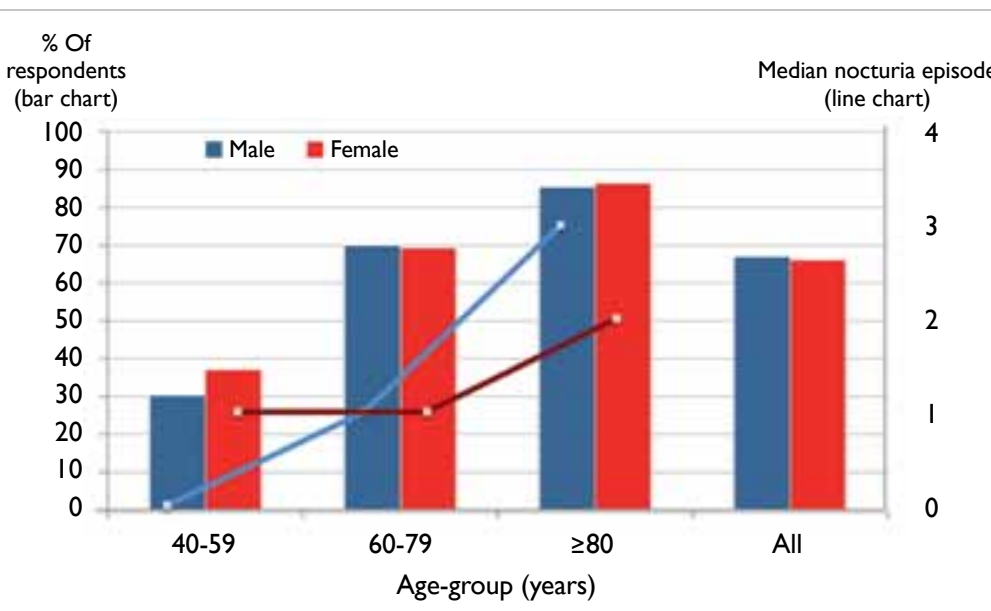

FIG 3. Nocturia among respondents with lower urinary tract symptoms 
TABLE 3. Storage and voiding symptoms regression analysis

\begin{tabular}{|c|c|c|c|c|c|c|c|c|}
\hline \multirow[t]{3}{*}{ Factor } & \multicolumn{4}{|c|}{ Storage symptoms } & \multicolumn{4}{|c|}{ Voiding symptoms } \\
\hline & \multicolumn{2}{|c|}{ Univariate analysis } & \multicolumn{2}{|c|}{ Multiple logistic regression } & \multicolumn{2}{|c|}{ Univariate analysis } & \multicolumn{2}{|c|}{ Multiple logistic regression } \\
\hline & $r$ & $P$ value & $\begin{array}{l}\text { Adjusted odds } \\
\text { ratio (95\% } \\
\text { confidence } \\
\text { interval) }\end{array}$ & $P$ value & $r$ & $P$ value & $\begin{array}{l}\text { Adjusted odds } \\
\text { ratio (95\% } \\
\text { confidence } \\
\text { interval) }\end{array}$ & $P$ value \\
\hline Age & 0.434 & $<0.001$ & $1.66(1.37-2.00)$ & $<0.001$ & 0.190 & $<0.001$ & $1.08(0.93-1.27)$ & 0.314 \\
\hline Sex & - & 0.052 & $1.17(0.75-1.80)$ & 0.490 & & $<0.001$ & $0.44(0.30-0.62)$ & $<0.001$ \\
\hline Education level (college) & -0.227 & $<0.001$ & & & -0.065 & 0.041 & & \\
\hline Coffee intake & -0.145 & $<0.001$ & & & -0.037 & 0.246 & & \\
\hline Tea intake & -0.104 & 0.001 & & & -0.057 & 0.071 & & \\
\hline Hypertension & - & $<0.001$ & $2.30(1.45-3.63)$ & $<0.001$ & - & $<0.001$ & $1.47(1.05-2.06)$ & 0.024 \\
\hline Diabetes & - & $<0.001$ & $2.72(1.30-5.70)$ & 0.008 & - & $<0.001$ & $2.11(1.42-3.14)$ & $<0.001$ \\
\hline IHD & - & 0.006 & & & - & $<0.001$ & $3.94(1.42-10.96)$ & 0.009 \\
\hline Stroke & - & 0.018 & & & - & 0.002 & $3.56(1.21-10.43)$ & 0.021 \\
\hline PHQ-9 & 0.257 & $<0.001$ & & & 0.275 & $<0.001$ & & \\
\hline SF-12v2-GH & 0.467 & $<0.001$ & & & 0.335 & $<0.001$ & & \\
\hline
\end{tabular}

Abbreviations: IHD = ischaemic heart disease; PHQ-9 = patient health questionnaire-9; SF- I 2V2-GH = Short Form-12v2 (general health)

Overactive bladder is a subset of storage LUTS, currently defined by the International Continence Society as urgency, with or without urgency incontinence, usually with frequency and nocturia. ${ }^{10}$ Our survey included overactive bladder symptom score as one of the tools to assess the prevalence of storage symptoms in our population. In the present study, the prevalence of any experience of urgency was $19.5 \%$ for men and $19.1 \%$ for women. This is in line with survey results from Europe, where Milsom et $\mathrm{al}^{15}$ reported the prevalence of overactive bladder symptoms to be $16.6 \%$, and from the US, where Stewart et $\mathrm{al}^{16}$ reported the prevalence of overactive bladder symptoms to be $16.0 \%$ in men and $16.9 \%$ in women. However, for clinically significant overactive bladder symptoms, urgency must be happening more than once per week. With this refinement, our study found that $8.6 \%$ of men and $5.3 \%$ of women reported urgency more than once per week. This group of patients warrants urological attention and intervention.

Voiding symptoms that are often associated with bladder outlet obstruction in men were also found to be common among women. In accordance with other studies in the literature, ${ }^{1,11,12}$ our survey confirmed that the prevalence of LUTS increases with age. In particular, storage symptoms were reported more often than voiding symptoms (Fig 2). Furthermore, age, hypertension, and diabetes were found to correlate with storage symptoms on multiple logistic regression (Table 3). Such observations conform to the findings by $\mathrm{Ng}$ et $\mathrm{al},{ }^{17}$ who noticed that in their cohort of 617 men with LUTS, 43\% had hypertension and $29 \%$ had dysglycaemia. In addition, $\mathrm{Ng}$ et $\mathrm{al}^{17}$ also reported that patients with moderate-to-severe LUTS had a significantly higher chance of having at least one cardiovascular risk factor during assessment. These results are echoed in an updated and more detailed analysis of 966 men with LUTS. ${ }^{18}$ Yee et al $^{18}$ demonstrated that the severity of LUTS was significantly positively correlated with Framingham score, which is an estimate of the risk of coronary heart disease taking into account of age, sex, smoking status, cholesterol levels, blood pressure, and hypertensive treatments. This supports the hypothesis that atherosclerosis leads to pelvis and bladder ischaemia, and that this might be one of the mechanisms leading to LUTS. ${ }^{19}$

Studies on the effect of caffeinated drinks on LUTS are scarce, and most have been on urinary incontinence. Davis et $\mathrm{al}^{20}$ reported that caffeine consumption was significantly associated with moderate-to-severe urinary incontinence in men from the US National Health and Nutrition Examination Survey. A similar finding was reported by Baek et $\mathrm{al}^{21}$ from the Korean National Health and Nutritional Examination Survey among postmenopausal women. However, our study did not find such a correlation. On the contrary, the consumption of caffeinated drink correlates negatively with storage symptoms in general (Table 3). One possible explanation for this contradiction is that respondents with significant storage symptoms had usually already cut down their caffeine intake. Thus, our survey could not illustrate the true impact of caffeinated drinks on overactive bladder 
symptoms. In addition to beverage consumption habits, a lower education level was another factor we found correlating with storage and voiding symptoms (Table 3 ). Another study proposed that knowledge on health and disease perception, which might be a function of education level, would lower the perceived severity of LUTS. ${ }^{22}$

In a prospective cohort of elderly men, Chung et $\mathrm{al}^{23}$ showed that the presence of moderate-tosevere LUTS at baseline was significantly associated with increased risk for being depressed at 2-year follow-up. The current study found that, individually, storage symptoms and voiding symptoms were correlated with a higher PHQ score, translating into a higher risk of depression. Furthermore, both storage and voiding symptoms were negatively correlated with all components of general health as measured by SF-12v2. These findings highlight the importance of LUTS management, considering its prevalence and its effect on individual well-being.

A significant percentage of respondents with LUTS did not seek medical help. A similar result has been observed in other Southeast Asian countries. ${ }^{1}$ Possible reasons for a low rate of medical help seeking behaviour include social stigma or a common belief that LUTS is unavoidable with ageing. A multinational cross-sectional survey on men seeking medical help for LUTS found that nocturia was the most common symptom among these patients (88\%). ${ }^{24}$ Our study demonstrated that, not only was nocturia a common symptom which drove respondents to seek medical help, it was also the most bothering symptom with the highest symptom score (Table 4). This suggests that nocturia is one of the most important symptoms that drive patients to seek medical help. However, management of nocturia is still a challenge for urologists. Cutting fluid intake alone was not found to be useful in prolonging the duration between the time retiring to bed and the first nocturia episode. ${ }^{25}$ Antidiuretics are presently the only treatment that provide consistent response in the setting of nocturnal polyuria. ${ }^{26}$

Limitations of the present study include the bias from self-reports to measure LUTS, which might be prone to inaccuracy when compared with physician assessment. However, a meticulous physical examination would not be possible in the setting of a large-scale epidemiological study. The telephone interview cam eliminate the limitation of illiteracy that might be present in self-administered questionnaires; however, such interviews might introduce bias from each interviewer's technique, as well as time pressure on respondents. The interviewers in our study were professional interviewers with vast experience in medical research. This minimised potential interview bias.

This population-based survey confirms that LUTS is common among both men and women.
TABLE 4. Symptom scores of patients seeking medical help

\begin{tabular}{llcc}
\hline Questionnaire & Symptoms & $\begin{array}{c}\text { Mean score } \\
\text { (standard } \\
\text { deviation) }\end{array}$ & $\begin{array}{c}\text { Median score } \\
\text { (interquartile } \\
\text { range) }\end{array}$ \\
\hline IPSS & Incomplete emptying & $0.97(1.77)$ & $0(2)$ \\
& Frequency & $0.70(1.47)$ & $0(1)$ \\
& Hesitancy & $0.83(1.53)$ & $0(1)$ \\
& Urgency & $0.97(1.67)$ & $0(1)$ \\
& Weak stream & $0.70(1.44)$ & $0(0)$ \\
& Straining & $0.40(1.07)$ & $0(0)$ \\
\hline \multirow{3}{*}{ OABSS } & Nocturia & $1.80(1.32)$ & $1.5(1)$ \\
& Daytime frequency & $0.47(0.57)$ & $0(1)$ \\
& Nocturia & $1.60(0.93)$ & $1.5(1)$ \\
& Urgency & $0.53(1.43)$ & $0(0)$ \\
\hline & Urge incontinence & $0.90(1.54)$ & $0(1)$ \\
\hline
\end{tabular}

Abbreviations: IPSS = International Prostate Symptom Score; OABSS = overactive bladder symptom score

Symptoms increase with age, significantly affecting patient mental and general health. Storage symptoms are more prominent than voiding symptoms, with nocturia being the most bothering symptom. A significant percentage of respondents with LUTS did not seek medical help. Future research and investigation should address this deficit.

\section{Author contributions}

All authors have made substantial contributions to the concept or design of this study; acquisition of data; analysis or interpretation of data; drafting of the manuscript; and critical revision for important intellectual content. All authors had full access to the data, contributed to the study, approved the final version for publication, and take responsibility for its accuracy and integrity.

\section{Conflicts of interest}

The authors have no conflicts of interest to disclose.

\section{Funding/support}

This research received no specific grant from any funding agency in the public, commercial, or not-for-profit sectors.

\section{Ethics approval}

Ethics approval was obtained from the Joint Chinese University of Hong Kong-New Territories East Cluster Clinical Research Ethics Committee (Ref. CRE-2016.588).

\section{References}

1. Chapple C, Castro-Diaz D, Chuang YC, et al. Prevalence of lower urinary tract symptoms in China, Taiwan, and South Korea: results from a cross-sectional, population-based study. Adv Ther 2017;34:1953-65.

2. Hutchison A, Farmer R, Chapple C, et al. Characteristics 
of patients presenting with LUTS/BPH in six European countries. Eur Urol 2006;50:555-61.

3. Sagnier PP, MacFarlane G, Teillac P, Botto H, Richard F, Boyle P. Impact of symptoms of prostatism on level of bother and quality of life of men in the French community. J Urol 1995;153(3 Pt 1):669-73.

4. Botelho EM, Elstad EA, Taubenberger SP, Tennstedt SL. Moderating perceptions of bother reports by individuals experiencing lower urinary tract symptoms. Qual Health Res 2011;21:1229-38.

5. Wong SY, Hong A, Leung J, Kwok T, Leung PC, Woo J. Lower urinary tract symptoms and depressive symptoms in elderly men. J Affect Disord 2006;96:83-8.

6. Census and Statistics Department, Hong Kong SAR Government. Available from: https://www.censtatd.gov. hk/home/. Accessed Nov 2016.

7. Homma Y, Yoshida M, Seki N, et al. Symptom assessment tool for overactive bladder syndrome-overactive bladder symptom score. Urology 2006;68:318-23.

8. Kroenke K, Spitzer RL, Williams JB. The PHQ-9: validity of a brief depression severity measure. J Gen Intern Med 2001;16:606-13.

9. Rosen RC, Riley A, Wagner G, Osterloh IH, Kirkpatrick J, Mishra A. The international index of erectile function (IIEF): a multidimensional scale for assessment of erectile dysfunction. Urology 1997;49:822-30.

10. Abrams P, Cardozo L, Fall M, et al. The standardisation of terminology in lower urinary tract function: report from the standardisation sub-committee of the International Continence Society. Urology 2003;61:37-49.

11. Coyne KS, Sexton CC, Thompson CL, et al. The prevalence of lower urinary tract symptoms (LUTS) in the USA, the UK and Sweden: results from the Epidemiology of LUTS (EpiLUTS) study. BJU Int 2009;104:352-60.

12. Irwin DE, Milsom I, Hunskaar S, et al. Population-based survey of urinary incontinence, overactive bladder, and other lower urinary tract symptoms in five countries: results of the EPIC study. Eur Urol 2006;50:1306-14.

13. Kobayashi M, Nukui A, Kamai T. Seasonal changes in lower urinary tract symptoms in Japanese men with benign prostatic hyperplasia treated with $\alpha_{1}$-blockers. Int Neurourol J 2017;21:197-203.

14. Choi HC, Kwon JK, Lee JY, Han JH, Jung HD, Cho KS. Seasonal variation of urinary symptoms in Korean men with lower urinary tract symptoms and benign prostatic hyperplasia. World J Mens Health 2015;33:81-7.

15. Milsom I, Abrams P, Cardozo L, Roberts RG, ThüroffJ, Wein AJ. How widespread are the symptoms of an overactive bladder and how are they managed? A population-based prevalence study. BJU Int 2001;87:760-6.

16. Stewart WF, Van Rooyen JB, Cundiff GW, et al. Prevalence and burden of overactive bladder in the United States. World J Urol 2003;20:327-36.

17. Ng CF, Wong A, Li ML, Chan SY, Mak SK, Wong WS. The prevalence of cardiovascular risk factors in male patients who have lower urinary tract symptoms. Hong Kong Med J 2007;13:421-6.

18. Yee $\mathrm{CH}$, Yip JS, Cheng NM, et al. The cardiovascular risk factors in men with lower urinary tract symptoms. World J Urol 2018 Aug 6. Epub ahead of print.

19. McVary K. Lower urinary tract symptoms and sexual dysfunction: epidemiology and pathophysiology. BJU Int 2006;97 Suppl 2:23-8.

20. Davis NJ, Vaughan CP, Johnson TM 2nd, et al. Caffeine intake and its association with urinary incontinence in United States men: results from National Health and Nutrition Examination Surveys 2005-2006 and 2007-2008. J Urol 2013;189:2170-4.

21. Baek JM, Song JY, Lee SJ, et al. Caffeine intake is associated with urinary incontinence in Korean postmenopausal women: results from the Korean National Health and Nutrition Examination Survey. PLoS One 2016;11:e0149311.

22. Yee CH, Li JK, Lam HC, Chan ES, Hou SS, Ng CF. The prevalence of lower urinary tract symptoms in a Chinese population, and the correlation with uroflowmetry and disease perception. Int Urol Nephrol 2014;46:703-10.

23. Chung RY, Leung JC, Chan DC, Woo J, Wong CK, Wong SY. Lower urinary tract symptoms (LUTS) as a risk factor for depressive symptoms in elderly men: results from a large prospective study in Southern Chinese men. PLoS One 2013;8:e76017.

24. Ho LY, Chu PS, Consigliere DT, et al. Symptom prevalence, bother, and treatment satisfaction in men with lower urinary tract symptoms in Southeast Asia: a multinational, cross-sectional survey. World J Urol 2018;36:79-86.

25. Teoh JY, Chan C, Ng CA, et al. Desmopressin oral lyophilisate lessens the burden of nocturia in the postTURP men sooner they go asleep-an action unreachable by fluid restriction alone but attenuated by aging. International Continence Society 2017 Florence. Available from: https://www.ics.org/2017/abstract/626. Accessed 11 Mar 2018.

26. Sakalis VI, Karavitakis M, Bedretdinova D, et al. Medical treatment of nocturia in men with lower urinary tract symptoms: systematic review by the European Association of Urology Guidelines Panel for male lower urinary tract symptoms. Eur Urol 2017;72:757-69. 